\title{
Intravenous fish oil lipid emulsions in critically ill patients: an updated systematic review and meta-analysis
}

\author{
William Manzanares ${ }^{1 *}$, Pascal L Langlois ${ }^{2}$, Rupinder Dhaliwal ${ }^{3}$, Margot Lemieux ${ }^{3}$ and Daren K Heyland ${ }^{3,4}$
}

\begin{abstract}
Introduction: Intravenous fish oil (FO) lipid emulsions (LEs) are rich in $\omega-3$ polyunsaturated fatty acids, which exhibit anti-inflammatory and immunomodulatory effects. We previously demonstrated that FO-containing LEs may be able to decrease mortality and ventilation days in patients who are critically ill. Since 2014, several additional randomized controlled trials (RCTs) of FO-containing LEs have been published. Therefore, the purpose of this systematic review was to update our previous systematic review with the aim of elucidating the efficacy of FO-containing LEs on clinical outcomes of patients who are critically ill.
\end{abstract}

Methods: We searched electronic databases from 1980 to 2014. We included four new RCTs conducted in critically ill adult patients in which researchers evaluated FO-containing LEs in parenterally or enterally fed patients.

Results: A total of 10 RCTs $(n=733)$ met inclusion criteria. The mean methodological score was 8 (range, 3 to 12). No effect on overall mortality was found. When we aggregated the results of five RCTs in which infections were reported, we found that FO-containing LEs significantly reduced infections (risk ratio (RR) $=0.64 ; 95 \%$ confidence interval $(\mathrm{Cl}), 0.44$ to $0.92 ; P=0.02$; heterogeneity $P^{2}=0 \%$ ). Subgroup analysis demonstrated that predominantly enteral nutrition-based trials showed a tendency toward a reduction in mortality ( $R R=0.69 ; 95 \% \mathrm{Cl}, 0.40$ to $1.18 ; P=0.18$; heterogeneity $P^{2}=35 \%$ ). High-quality trials showed a significant reduction in hospital length of stay (LOS) (weighted mean difference $=-7.42 ; 95 \% \mathrm{Cl},-11.89$ to $-2.94 ; P=0.001)$, whereas low-quality trials had no effect $(P=0.45)$. The results of the test for subgroup differences in hospital LOS was significant $(P=0.001)$.

Conclusion: FO-containing LEs may be associated with a reduction in infections and also could be associated with a reduction in duration of ventilation and hospital LOS. Further large-scale RCTs are warranted and should be aimed at consolidating potential positive treatment effects.

\section{Introduction}

Lipid emulsions (LEs), which are an integral part of a parenteral nutrition $(\mathrm{PN})$ regimen, provide exogenous fatty acids, which are commonly used by cells as an energy-dense source of fuel calories (approximately 9 $\mathrm{kcal} / \mathrm{g}$ ), cell membrane components and biologically active substrates [1-3]. In patients who are critically ill, commonly used LEs have provided long-chain triglycerides (LCTs), particularly soybean oil (SO), with a high percentage of $\omega-6$ polyunsaturated fatty acids (PUFAs;

\footnotetext{
* Correspondence: wmanzanares@adinet.com.uy

${ }^{1}$ Intensive Care Unit, Faculty of Medicine-Universidad de la República (UdeLaR) University Hospital: Dr. Manuel Quintela, Italia Av. 14th Floor, Montevideo 11600, Uruguay

Full list of author information is available at the end of the article
}

18:2 $\omega-6)$ [4]. Nonetheless, over the last few decades, several different $\mathrm{SO}$-sparing strategies have been developed, which are defined as alternative oil-based LEs. Fish oil (FO)-containing LEs are a type of alternative LE that are high in $\omega$-3 PUFAs (18:3 $\omega-3)$. Examples are eicosapentaenoic acid (EPA) and docosahexaenoic acid (DHA) [5]. According to the capacity of EPA and DHA to modulate the synthesis of eicosanoids, the activity of nuclear receptor and nuclear transcription factors, and the production of resolvins, these fatty acids have long been recognized as having anti-inflammatory and immunomodulatory effects [6]. In a secondary analysis of data from the International Nutrition Survey, Edmunds et al. [7] demonstrated that FO-containing LEs were able to reduce the duration of mechanical ventilation $(\mathrm{MV})$ and 
time of intensive care unit (ICU) discharge alive compared with SO-based LEs. Over the last few years, there have been several RCTs on FO-containing LEs in patients who are critically ill in which investigators reported relevant clinical outcomes, which have been included in previous meta-analyses [8-10].

In 2012, in a systematic review and meta-analysis, Pradelli et al. [8] concluded that in elective surgery and critically ill patients, parenteral FO-containing LEs were associated with a significant reduction in infections, although Palmer et al. [9], in another systematic review, were unable to find similar results in ICU patients.

In 2013, after aggregating six RCTs evaluating the effect of parenteral FO-containing LEs on relevant clinical outcomes in a heterogeneous ICU patient population [10], we demonstrated that FO-containing LEs may be able to decrease mortality (risk ratio (RR), 0.71; 95\% confidence interval $(\mathrm{CI}), 0.49$ to $1.04 ; P=0.08$ ) and also reduce the duration of $\mathrm{MV}$ (weighted mean difference $(\mathrm{WMD})=-1.41 ; 95 \% \mathrm{CI},-3.43$ to $0.61 ; P=0.17$ ) [10]. Nonetheless, since 2014, several RCTs evaluating clinical effects of FO-containing LEs as compared with other LEs (SO, medium-chain triglycerides (MCTs) and/or LCTs or olive oil (OO)) in ICU patients being treated with PN- and EN-based strategies have been published. Therefore, with the aim of elucidating the efficacy of parenteral FO-containing LEs in patients who are critically ill, we performed an update of our previous systematic review and meta-analysis of the literature.

\section{Methods}

\section{Search strategy and study identification}

A literature review was conducted to identify in MEDLINE, Embase, CINAHL, the Cochrane Central Register of Controlled Trials and the Cochrane Database of Systematic Reviews all relevant RCTs published between 1980 and November 2014. The following keywords or medical subject headings were used: "randomized," "clinical trial," "nutrition support," "artificial feeding," "parenteral nutrition," "pharmaconutrition," "omega-3 fatty acids," "fish oils," "lipid emulsions," "intensive care," "critical illness" and "critically ill." We did not restrict our search to only articles written in English.

\section{Eligibility criteria}

Trials were included if they met the following characteristics:

1. Type of study: RCT with a parallel group.

2. Population: critically ill adult patients ( $\geq 18$ years of age), defined as patients admitted to an ICU. If the study population was unclear, we considered a mortality rate higher than $5 \%$ in the control group to be consistent with critical illness. We excluded
RCTs performed in elective surgery patients (such as open-heart surgery patients) even if patients were cared for in an ICU in the postoperative period.

3. Intervention: intravenous FO-containing LEs as part of $\mathrm{PN}$ or as a pharmaconutrient strategy (enterally fed patients).

4. Control: EN, PN with SO-based LEs or a non-FObased LE, as well as saline solution. Non-FO LEs and saline solution were defined as non-FO lipids or non-FO strategies.

5. Outcomes: Overall mortality was the primary outcome for this meta-analysis. Secondary outcomes were infections, ICU and hospital length of stay (LOS) and MV days. As in previous meta-analyses conducted by our group, we excluded those trials that reported only nutrition, biochemical, metabolic or immunologic outcomes. The methodological quality of the included trials was assessed in duplicate independently by two reviewers using a data abstraction form with a scoring system [11] from 0 to 14 according to the following criteria:

a. The extent to which randomization was concealed

b. Blinding

c. Analysis based on the intention-to-treat (ITT) principle

d. Comparability of groups at baseline

e. Extent of follow-up

f. Description of treatment protocol

g. Cointerventions

h. Definition of clinical outcomes

Consensus between both reviewers on the individual scores of each of the categories was obtained. We attempted to contact the authors of included studies and requested additional information not contained in published articles. We designated studies as level I if all of the following criteria were fulfilled: concealed randomization, blinded outcome adjudication and an ITT analysis, which are the strongest methodological tools to reduce bias. A study was considered as level II if any one of the abovedescribed characteristics were unfulfilled.

\section{Data synthesis}

The primary outcome of the systematic review was mortality (hospital mortality or if not reported, 28 days or ICU mortality). The definitions of infectious complications as defined by authors of individual trials were used. We analyzed data using RevMan 5.3 (Cochrane IMS, Oxford, UK) with a random effects model. We combined data from all trials to estimate the pooled risk ratio (RR) with 95\% confidence intervals (CIs) for mortality and infections and overall weighted mean difference (WMD) with 95\% confidence intervals for LOS 
data. Pooled RRs were calculated using the MantelHaenszel estimator, and WMDs were estimated by the inverse variance approach. The random effects model of DerSimonian and Laird was used to estimate variances for the Mantel-Haenszel [12] and inverse variance estimators. RRs were undefined and excluded for studies with no event in either arm. Heterogeneity was tested by a weighted Mantel-Haenszel $X^{2}$ test and quantified by the $\mathrm{I}^{2}$ statistic as implemented in RevMan. Differences between subgroups were analyzed using the test of subgroup differences described by Deeks et al. [13], and the results expressed using the $P$-values.

The possibility of publication bias was assessed by generating funnel plots and testing asymmetry of outcomes using methods proposed by Rucker et al. [14]. We considered $P<0.05$ to be statistically significant and $P<0.20$ as an indicator of trend.

\section{Subgroup analysis}

We performed a predefined subgroup analysis to assess a number of possible influences on the effects of intravenous FO-containing LEs on clinical outcomes. We first examined the effect of parenteral FO-containing LEs in the context of PN (PN-based trials) versus predominantly EN-based trials [15-18], which included EN alone, EN with PN, EN with oral (PO) or EN, PN and PO together. In addition, as the trial quality can influence clinical findings, we postulated that trials with lower quality (defined as level II studies) may demonstrate a greater treatment effect than those trials with higher quality (level I studies), which were previously defined.

\section{Results}

A total of 54 relevant citations were identified in the search of electronic bibliographic databases and a review of reference lists in related articles. We excluded 44 trials for the following reasons: 25 trials [19-43] did not include ICU patients (mostly elective surgery and cancer patients); 10 trials [44-53] did not evaluate clinically important outcomes; 2 trials $[54,55]$ were published as abstracts, and we were unable to obtain the data from the authors to complete our data abstraction process; 2 trials [56,57] were conducted in a pediatric population; 2 trials $[58,59]$ had a short duration of intervention (a single infusion during the study period); and 3 articles $[8,9,60]$ were systematic reviews and meta-analyses (Figure 1).

In the end, ten RCTs [15-18,61-66], including four new trials $[17,18,65,66]$ published since our last metaanalysis, met the inclusion criteria and were finally included in this systematic review (see Tables 1 and 2). The ten trials comprised an aggregate total of $733 \mathrm{pa}-$ tients. There was considerable heterogeneity in the interventions tested in these trials. Among RCTs in PN-fed patients, three trials [63-65] compared a LCT + MCT + FO LE with an MCT + LCT LE, two trials $[61,62]$ compared a FO + LCT LE with a LCT LE and one trial [66] compared a $\mathrm{FO}+\mathrm{OO}$ LE with an OO-containing LE. Among the four RCTs in which investigators evaluated predominantly EN-fed patients [15-18], one trial [16] compared supplementation of EN or PO diet with a parenteral FO-containing LE to EN or PO diet with intravenous normal saline, one trial [15] compared supplementation of EN with a parenteral FO-containing LE to EN alone, one trial [17] compared supplementation of EN, PN or PO diet

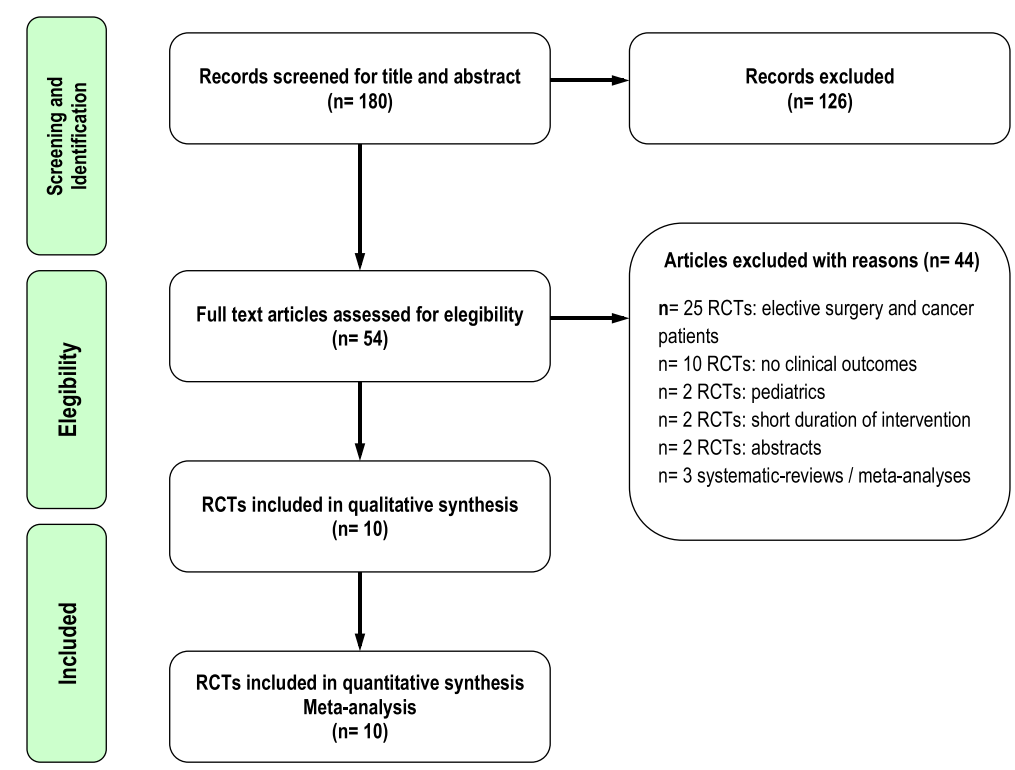

Figure 1 Flow diagram of the literature search according to the Quality of Reporting of Meta-analyses statement [72]. 
Table 1 Randomized clinical trials evaluating parenteral fish oil-containing lipid emulsions in critically ill patients ${ }^{\mathrm{a}}$

\begin{tabular}{|c|c|c|c|c|c|c|c|}
\hline Study & Population & Methods (score) & Intervention & Mortality (\%) ${ }^{\mathrm{b}}$ & & Infections (\%) ${ }^{c}$ & \\
\hline & & & & & & & \\
\hline Grecu et al., 2003 ${ }^{d}[62]$ & $\begin{array}{l}\text { Patients with } \\
\text { abdominal sepsis }\end{array}$ & C.Random: Yes & $\begin{array}{l}\text { PN + Omegaven (10\% FO; Fresenius Kabi, } \\
\text { Bad Homburg, Germany) plus LCT vs. }\end{array}$ & Omegaven + LCT & LCT & Omegaven & LCT \\
\hline & $N=54$ & ITT: Yes & & ICU & ICU & VAP & VAP \\
\hline & (15 of 54 in ICU) & Blinding: Double & & $2 / 28(7)$ & $3 / 26(12)$ & $0 / 8$ & $1 / 7(14)$ \\
\hline & & (12) & & & & & \\
\hline Friesecke et al., 2008 [63] & Medical ICU patients & C.Random: Yes & PN + Lipofundin (B Braun, Melsungen, & $\mathrm{MCT}+\mathrm{LCT}+\mathrm{FO}$ & $\mathrm{LCT}+\mathrm{MCT}$ & $\mathrm{MCT}+\mathrm{LCT}+\mathrm{FO}$ & $\mathrm{LCT}+\mathrm{MCT}$ \\
\hline & $N=166$ & ITT: Yes & $\begin{array}{l}\text { Germany) MC ( } 150 \% \text { LC I + 50\% MC I) + } \\
\text { Omegaven (10\% FO) vs. PN with }\end{array}$ & 28 days & 28 days & 10/83 (12) & $11 / 82(13)$ \\
\hline & & Blinding: Double & Lipofundin MCT (50\% LCT + 50\% MCT) & 18/83 (22) & $22 / 82(27)$ & & \\
\hline & & (10) & & & & & \\
\hline Wang et al., 2009 [61] & $\begin{array}{l}\text { Severe acute pancreatitis } \\
\text { patients in ICU }\end{array}$ & C.Random: No & $\begin{array}{l}\text { PN + Omegaven ( } 10 \% \text { FO) plus } \\
\text { Lipovenos (LCT, soybean oil; Fresenius }\end{array}$ & Omegaven & LCT & Omegaven & LCT \\
\hline & $N=56$ & ITT: Yes & $\begin{array}{l}\text { Kabi) ( } \omega 3: \omega 6 \text { ratio was 1:4) vs. PN with } \\
\text { Lipovenos (LCT, soybean oil). Both }\end{array}$ & ICU & ICU & $6 / 28(21)$ & $9 / 28(32)$ \\
\hline & & Blinding: Double & received same amounts of lipids & $0 / 28(0)$ & $2 / 28(7)$ & & \\
\hline & & (11) & & & & & \\
\hline Barbosa et al., 2010 [64] & $\begin{array}{l}\text { ICU patients with SIRS } \\
\text { or sepsis requiring PN }\end{array}$ & C.Random: Yes & $\begin{array}{l}\text { PN + Lipolus (50\% MCT, 40\% LCT soybean } \\
\text { oil, 10\% FO; B Braun) vs. PN with NuTRIflex }\end{array}$ & $\mathrm{MCT}+\mathrm{LCT}+\mathrm{FO}$ & $\mathrm{MCT}+\mathrm{LCT}$ & $\mathrm{MCT}+\mathrm{LCT}+\mathrm{FO}$ & $\mathrm{MCT}+\mathrm{LCT}$ \\
\hline & $N=25$ & ITT: Yes & $\begin{array}{l}\text { Lipid Special (50\% MCT, 50\% LCT, soybean } \\
\text { oil; B Braun). Both received same amounts }\end{array}$ & 5 days & 5 days & NR & NR \\
\hline & & Blinding: Single & of lipids (about 1 g/kg/day) & $2 / 13(15)$ & $1 / 10(10)$ & & \\
\hline & & (10) & & 28 days & 28 days & & \\
\hline & & & & $4 / 13(31)$ & $4 / 10(40)$ & & \\
\hline Gupta et al., 2011 [15] & $\begin{array}{l}\text { ICU patients with } \\
\text { suspected ARDS }\end{array}$ & C.Random: Yes & $\begin{array}{l}\text { EN (standard diet) + Omegaven 10\% } \\
(\omega 3: \omega 6 \text { ratio was 1:4) vs. EN }\end{array}$ & Omegaven & Standard & NR & NR \\
\hline & $N=61$ & ITT: Yes & (standard diet) & ICU & EN & & \\
\hline & & Blinding: Double & & $7 / 31(23)$ & ICU & & \\
\hline & & (9) & & Hospital & $13 / 30(43)$ & & \\
\hline & & & & 9/31 (29) & Hospital & & \\
\hline & & & & & $14 / 30(47)$ & & \\
\hline Khor et al., 2011 [16] & $\begin{array}{l}\text { ICU patients with severe } \\
\text { sepsis/septic shock }\end{array}$ & C.Random: Yes & $\begin{array}{l}\text { Supplementation with } 100 \mathrm{ml} \text { of } 10 \% \\
\text { Omegaven }(10 \mathrm{~g} \text { of refined FO, EPA } 12.5 \text { to }\end{array}$ & NR & NR & NR & NR \\
\hline & $N=28$ & ITT: No & $\begin{array}{l}28.2 \mathrm{~g} / \mathrm{L} \text {, DHA } 14.4 \text { to } 30.9 \mathrm{~g} / \mathrm{L}) \text { vs. } 100 \mathrm{ml} \\
\text { of } 0.9 \% \text { normal saline }\end{array}$ & & & & \\
\hline & & Blinding: Double & & & & & \\
\hline & & (8) & & & & & \\
\hline
\end{tabular}


Table 1 Randomized clinical trials evaluating parenteral fish oil-containing lipid emulsions in critically ill patients ${ }^{\mathrm{a}}$ (Continued)

\begin{tabular}{|c|c|c|c|c|c|c|c|}
\hline \multirow[t]{4}{*}{ Burkhart et al., 2013 [18] } & $\begin{array}{l}\text { ICU patients } \\
\text { with sepsis }\end{array}$ & C.Random: ? & \multirow{4}{*}{$\begin{array}{l}2 \mathrm{ml} / \mathrm{kg} / \text { day Omegaven vs. no parenteral } \\
\text { FO. Both groups received EN and/or PN } \\
\text { without added FO at the discretion of } \\
\text { the clinician. }\end{array}$} & Omegaven & No Omegaven & NR & NR \\
\hline & \multirow[t]{3}{*}{$N=50$} & ITT: Yes & & Hospital & Hospital & & \\
\hline & & $\begin{array}{l}\text { Blinding: Single } \\
\text { (assessor) }\end{array}$ & & $13 / 25(52)$ & $13 / 25(52)$ & & \\
\hline & & (8) & & & & & \\
\hline \multirow[t]{7}{*}{ Grau-Carmona et al., 2014 [65] } & $\begin{array}{l}\text { Medical and surgical } \\
\text { patients requiring PN }\end{array}$ & C.Random: Yes & \multirow{7}{*}{$\begin{array}{l}\text { PN + Lipoplus (50\% MCT, 40\% LCT soybean } \\
\text { oil, 10\% FO; B Braun) vs. PN + Lipofundin } \\
\text { (50\% LCT + 50\% MCT) }\end{array}$} & $\mathrm{MCT}+\mathrm{LCT}+\mathrm{FO}$ & MCT + LCT ICU & $\mathrm{MCT}+\mathrm{LCT}+\mathrm{FO}$ & $\mathrm{MCT}+\mathrm{LCT}$ \\
\hline & \multirow[t]{6}{*}{$N=175$} & ITT: Yes & & ICU & 16/78 (20.5) & $17 / 81(21)$ & 29/78 (37.2) \\
\hline & & Blinding: Double & & 26/81 (32.5) & Hospital & & \\
\hline & & (10) & & Hospital & $6 / 78(9.7)$ & & \\
\hline & & & & $6 / 81(11.1)$ & 6 months & & \\
\hline & & & & 6 months & 2/78 (3.6) & & \\
\hline & & & & 2/81 (4.3) & & & \\
\hline \multirow[t]{4}{*}{ Gultekin et al., 2014 [66] } & $\begin{array}{l}\text { ICU patients } \\
\text { needing TPN }\end{array}$ & C.Random: ? & \multirow{4}{*}{$\begin{array}{l}\text { PN + Omegaven (10\% FO) plus ClinOleic } \\
\text { ( } 80 \% \text { olive oil, } 20 \% \text { soybean oil; Baxter } \\
\text { Healthcare, Compton, UK) vs. PN + ClinOleic }\end{array}$} & Omegaven + olive oil & Olive oil & NR & NR \\
\hline & \multirow[t]{3}{*}{$N=58$} & ITT: Other & & Unspecified & Unspecified & & \\
\hline & & Blinding: Double & & $8 / 16(50)$ & $7 / 16(44)$ & & \\
\hline & & (3) & & & & & \\
\hline \multirow[t]{5}{*}{ Hall et al., 2014 [17] } & $\begin{array}{l}\text { ICU patients } \\
\text { with sepsis }\end{array}$ & C.Random: ? & \multirow{5}{*}{$\begin{array}{l}\text { Omegaven dosed at } 0.2 \mathrm{~g} \text { of } \mathrm{FO} / \mathrm{kg} / \text { day } \\
\text { given at a rate of } 0.05 \mathrm{~g} \text { of } \mathrm{FO} / \mathrm{kg} / \mathrm{day} \mathrm{vs} \text {. no } \\
\text { FO. Both groups received EN and } / \mathrm{or} \mathrm{PN} \text { at } \\
\text { the discretion of the clinician. }\end{array}$} & Omegaven & No Omegaven & Omegaven & No Omegaven \\
\hline & \multirow[t]{4}{*}{$N=60$} & ITT: Yes & & Hospital & Hospital & $3 / 30(10)$ & $5 / 30(16.7)$ \\
\hline & & Blinding: No & & $4 / 30(13.3)$ & 9/30 (30) & & \\
\hline & & (9) & & 28 days & 28 days & & \\
\hline & & & & 4/30 (13.3) & 8/30 (26.7) & & \\
\hline
\end{tabular}

${ }^{a}$ These studies compared fish oil ( $\left.\omega-3\right)$-containing emulsions in parenteral nutrition-fed patients with long-chain triglycerides or long-chain triglycerides + medium-chain triglycerides. ARDS, Acute respiratory distress syndrome; C.Random, Concealed randomization; DHA, Docosahexaenoic acid; EPA, Eicosapentaenoic acid; FO, Fish oil; ICU, Intensive care unit; ITT, Intention to treat; LCT, Long-chain triglycerides; LE, Lipid emulsion; MCT, Medium-chain triglycerides; NA, Non-attributable; NR, Non-reported; PN, Parenteral nutrition; SIRS, Systemic inflammatory response syndrome; TPN, Total parenteral nutrition; VAP, Ventilator-associated pneumonia;

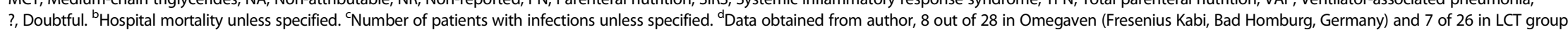
were in ICU. 
Table 2 Outcomes of included trials on fish oil strategies using lipid emulsions ${ }^{a}$

\begin{tabular}{|c|c|c|c|c|c|c|}
\hline \multirow{2}{*}{$\begin{array}{l}\text { Study } \\
\text { FO }\end{array}$} & \multicolumn{2}{|l|}{ LOS in days } & \multicolumn{2}{|l|}{ Ventilator days } & \multicolumn{2}{|l|}{ Other } \\
\hline & & & & & & \\
\hline \multirow[t]{5}{*}{ Grecu et al., $2003^{b}[62]$} & $\begin{array}{l}\text { Omegaven } \\
\text { (Fresenius Kabi, Bad Homburg, Germany) }\end{array}$ & LCT & Omegaven & LCT & Omegaven & LCT \\
\hline & ICU & ICU & $2.83 \pm 1.62(8)$ & $5.23 \pm 2.80(7)$ & \multicolumn{2}{|c|}{ Patients undergoing reoperation for septic episode } \\
\hline & $3.32 \pm 1.48(8)$ & $9.28 \pm 3.08(7)$ & & & $2 / 28(7)$ & $8 / 26(31)$ \\
\hline & Hospital & Hospital & & & & \\
\hline & $11.68 \pm 2.04(28)$ & $20.46 \pm 3.27(26)$ & & & & \\
\hline \multirow[t]{7}{*}{ Friesecke et al., 2008 [63] } & FO & LCT & $\mathrm{LCT}+\mathrm{MCT}+\mathrm{FO}$ & $\mathrm{LCT}+\mathrm{MCT}$ & $\mathrm{LCT}+\mathrm{MCT}+\mathrm{FO}$ & $\mathrm{LCT}+\mathrm{MCT}$ \\
\hline & ICU & ICU & $22.8 \pm 22.9(83)$ & $20.5 \pm 19.0(82)$ & Urinary tract infec & \\
\hline & $28 \pm 25(83)$ & $23 \pm 20(82)$ & & & $6 / 83(7)$ & 4/82 (5) \\
\hline & & & & & \multicolumn{2}{|c|}{ Catheter-related infections } \\
\hline & & & & & $1 / 83(1)$ & 3/83 (4) \\
\hline & & & & & \multicolumn{2}{|c|}{ Total EN energy intake (kcal/kg) } \\
\hline & & & & & $22.2 \pm 5.5$ & $21.6 \pm 5.6$ \\
\hline \multirow[t]{3}{*}{ Wang et al., 2009 [61] } & NR & NR & NR & NR & Omegaven & LCT \\
\hline & & & & & \multicolumn{2}{|c|}{ Surgery of infected pancreatic necrosis } \\
\hline & & & & & $3 / 28(11)$ & $6 / 28(21)$ \\
\hline \multirow[t]{5}{*}{ Barbosa et al., 2010 [64] } & $\mathrm{MCT}+\mathrm{LCT}+\mathrm{FO}$ & $\mathrm{MCT}+\mathrm{LCT}$ & $\mathrm{MCT}+\mathrm{LCT}+\mathrm{FO}$ & $\mathrm{MCT}+\mathrm{LCT}$ & $\mathrm{MCT}+\mathrm{LCT}+\mathrm{FO}$ & $\mathrm{MCT}+\mathrm{LCT}$ \\
\hline & ICU & ICU & $10 \pm 14.4(13)$ & $11 \pm 12.64(10)$ & $2,057 \pm 418 \mathrm{kcal}$ & $1,857 \pm 255 \mathrm{kcal}$ \\
\hline & $12 \pm 14.4^{c}(13)$ & $13 \pm 12.6^{c}(10)$ & & & & \\
\hline & Hospital & Hospital & & & & \\
\hline & $22 \pm 25.2^{c}(13)$ & $55 \pm 50.6^{c}(10)$ & & & & \\
\hline \multirow[t]{5}{*}{ Gupta et al., 2011 [15] } & Omegaven & Standard EN & Omegaven & Standard EN & & \\
\hline & ICU & ICU & $11.78 \pm 10.63(31)$ & $10.71 \pm 14.55(30)$ & & \\
\hline & $15.96 \pm 7.57(31)$ & $15.88 \pm 6.47(30)$ & & & & \\
\hline & Hospital & Hospital & & & & \\
\hline & $21.5 \pm 13.49(31)$ & $26.63 \pm 18.22(30)$ & & & & \\
\hline \multirow[t]{5}{*}{ Khor et al., 2011 [16] } & Omegaven & Saline & Omegaven & Saline & & \\
\hline & ICU & ICU & $13.0 \pm 10.1(9)$ & $11.6 \pm 9.5(5)$ & & \\
\hline & $10.3 \pm 8.4(14)$ & $8.4 \pm 6.5(13)$ & & & & \\
\hline & Hospital & Hospital & & & & \\
\hline & $19.6 \pm 7.4(14)$ & $17.5 \pm 6.0(13)$ & & & & \\
\hline
\end{tabular}


Table 2 Outcomes of included trials on fish oil strategies using lipid emulsions ${ }^{\mathrm{a}}$ (Continued)

\begin{tabular}{|c|c|c|c|c|c|c|}
\hline \multirow[t]{5}{*}{ Burkhart et al., 2013 [18] } & Omegaven & No Omegaven & NR & NR & Omegaven & No Omegaven \\
\hline & ICU & ICU & & & \multicolumn{2}{|l|}{ Subsyndromal delirium } \\
\hline & 5 (3 to 22$)$ & $6(2$ to 33$)$ & & & $5(25)$ & $6(29)$ \\
\hline & & & & & \multicolumn{2}{|l|}{ Sepsis associated delirium } \\
\hline & & & & & $15(75)$ & $15(71)$ \\
\hline \multirow[t]{5}{*}{ Grau-Carmona et al., 2014 [65] } & $M C T+L C T+F O$ & MCT + LCT & $M C T+L C T+F O$ & MCT + LCT & $\mathrm{MCT}+\mathrm{LCT}+\mathrm{FO}$ & $\mathrm{MCT}+\mathrm{LCT}$ \\
\hline & ICU & ICU & $8.41 \pm 6.61$ & $9.2 \pm 6.0$ & \multicolumn{2}{|c|}{ Parenteral lipid intake $[(\mathrm{g} / \mathrm{kg} \mathrm{BW}) / \mathrm{d}]$} \\
\hline & $18.9 \pm 15.5$ & $21.8 \pm 20.9$ & & & $1.04 \pm 0.12$ & $1.05 \pm 0.13$ \\
\hline & Hospital & Hospital & & & PN kcal & \\
\hline & $41.1 \pm 41.0$ & $42.5 \pm 28.5$ & & & $1,737 \pm 353$ & $1,782 \pm 312$ \\
\hline \multirow[t]{4}{*}{ Gultekin et al., 2014 [66] } & Omegaven + olive & Olive oil & NR & NR & Omegaven + olive oil & Olive oil \\
\hline & Hospital & Hospital & & & & \\
\hline & $31.6 \pm 4.3$ & $30.6 \pm 4.3$ & & & $27.5 \pm 1.5 \mathrm{kcal} / \mathbf{k g} / \mathrm{day}$ & $15.8 \pm 1.5 \mathrm{kcal} / \mathbf{k g} / \mathbf{d a y}$ \\
\hline & & & & & $1.3 \pm 0.2$ g protein $/ \mathbf{k g} /$ day & $1.1 \pm 0.1 \mathrm{~g}$ protein $/ \mathbf{k g} /$ day \\
\hline \multirow[t]{5}{*}{ Hall et al., 2014 [17] } & Omegaven & No Omegaven & $\begin{array}{l}\text { NR (reported as } \\
\text { free ventilator days) }\end{array}$ & $\begin{array}{l}\text { NR (reported as } \\
\text { free ventilator days) }\end{array}$ & & \\
\hline & ICU & ICU & & & & \\
\hline & $8.8 \pm 7.7$ & $12.3 \pm 12.4$ & & & & \\
\hline & Hospital & Hospital & & & & \\
\hline & $26.7 \pm 18.2$ & $33.5 \pm 30.4$ & & & & \\
\hline
\end{tabular}

These studies compared fish oil ( $\omega-3)$-containing emulsions in parenteral nutrition-fed patients vs. LCT or LCT + MCT. EN, Enteral nutrition; FO, Fish oil; ICU, Intensive care unit; LCT, Long-chain triglycerides;

MCT, Medium-chain triglycerides; IT, Intention to treat; NR, Not reported. ${ }^{\mathrm{b}}$ Data obtained from author, 8 of 28 in Omegaven (Fresenius Kabi, Bad Homburg, Germany) group and 7 of 26 in LCT group were in the ICU. ${ }^{\mathrm{c} C o n v e r t e d ~ s t a n d a r d ~ e r r o r ~ o f ~ t h e ~ m e a n ~ t o ~ s t a n d a r d ~ d e v i a t i o n . ~}$ 
with a parenteral FO-containing LE to EN or PN or PO diet alone, and one trial [18] compared supplementation of EN or PN with a parenteral FO-containing emulsion to $\mathrm{EN}$ or PN alone. We reached $100 \%$ agreement for inclusion of trials in the present review. The mean methodological score of all trials was 9 (range, 3 to 12). Randomization was concealed in six $(60 \%)$ of the ten trials, ITT analysis was performed in eight trials $(80 \%)$ and seven trials $(70 \%)$ were double-blinded. There were five level I studies [15,61-64] and five level II studies $[16-18,61,66]$. The details of the methodological quality of the individual trials are shown in Table 1.

\section{Meta-analyses of primary and secondary outcomes Primary outcome}

Mortality When the data from nine RCTs [15,17,18,61-66] evaluating mortality as one of the outcomes were aggregated, FO-containing strategies did not achieve a statistically significant reduction in mortality $(R R=0.90 ; 95 \% \mathrm{CI}$, 0.67 to $1.20 ; P=0.46$; heterogeneity $I^{2}=0 \%$ ) (see Figure 2 ). Heterogeneity was not significant $(P=0.29)$.

\section{Secondary outcomes}

Infectious complications When the results of five RCTs $[17,61-63,65]$ that reported infectious complications were aggregated, FO-containing LEs significantly reduced infections $(\mathrm{RR}=0.64 ; 95 \% \mathrm{CI}, 0.44$ to $0.92 ; P=0.02$; heterogeneity $I^{2}=0 \%$ ) (see Figure 3 ). Similarly, after excluding the Grecu et al. [62] study because the authors reported only ventilator-associated pneumonia (VAP), the same effect was shown $(\mathrm{RR}=0.65 ; 95 \% \mathrm{CI}, 0.44$ to $0.94 ; P=0.02$; heterogeneity $\left.I^{2}=0 \%\right)$.

Mechanical ventilation The aggregation of six RCTs [15,16,62-65] on FO-containing LEs in which the researchers reported on MV showed a trend toward reduction in the number of days on MV (WMD, $-1.14 ; 95 \%$ CI, -2.67 to $0.38 ; P=0.14$; heterogeneity $I^{2}=0 \%$ ) (see Figure 4).

Hospital length of stay When the data from seven RCTs [15-17,62,64-66] in which researchers reported on hospital length of stay were aggregated, FO-containing strategies showed a trend toward reduction in hospital LOS, without reaching statistical significance (WMD = $-3.71 ; 95 \% \mathrm{CI},-9.31$ to $1.88 ; P=0.19$ ) (see Figure 5 ). The heterogeneity was significant $\left(P<0.00001 ; I^{2}=87 \%\right)$.

ICU length of stay The seven RCTs [15-17,62-65] evaluating ICU length of stay were aggregated, but we did not find any effects related to FO-containing LEs in parenterally fed patients (WMD $=-1.42 ; 95 \% \mathrm{CI},-4.53$ to $1.69 ; P=0.37$ ) (see Figure 6). However, the heterogeneity analysis was statistically significant $\left(P=0.01 ; I^{2}=63 \%\right)$.

\section{Subgroup analyses \\ Parenteral nutrition-based trials versus predominantly enteral nutrition-based trials}

In six trials, researchers investigated the administration of FO-containing LEs in parenterally fed patients [61-66], whereas in four trials [15-18], parenteral FO supplementation was studied in the context of patients receiving predominantly EN. There were no significant differences in any endpoint between trials of PN- versus EN-based nutritional strategies. However, in those EN-based trials $[15,17,18]$ in which patients received intravenous FOcontaining LEs, this pharmaconutrient strategy showed a tendency toward a reduction in mortality $(\mathrm{RR}=0.69 ; 95 \%$ CI, 0.40 to $1.18 ; P=0.18$; heterogeneity $I^{2}=35 \%$ ) (see Figure 2). When we examined the effect of FO-containing LEs in PN-based trials versus predominantly EN-based trials, the test for subgroup differences on overall mortality showed a trend $(P=0.19)$.

\section{Effect of study quality on outcomes}

Similarly to low-quality trials $[17,18,61,66]$, the higherquality trials [15,62-65] did not show any effect on mortality ( $P=0.58$ in both subgroups). Nonetheless, a statistically significant effect of FO-containing LEs on the reduction of infections was shown in the higher-quality trials $[62,63,65]$ $(\mathrm{RR}=0.64 ; 95 \% \mathrm{CI}, 0.42$ to $0.97 ; P=0.04$; heterogeneity $I^{2}=0 \%$, whereas trials with lower methods scores did not show any significant effect $(\mathrm{RR}=0.65 ; 95 \% \mathrm{CI}, 0.31$ to $1.35 ; P=0.25$; heterogeneity $I^{2}=0 \%$ ). However, the overall tests for significance did not reveal statistically significant differences between these subgroups $(P=0.97)$.

The effect of study quality on MV did not show any significant effect, although one low-quality trial [16] explored this outcome. The test for subgroup differences on MV days was not significant $(P=0.64)$. With regard to hospital LOS, higher-quality trials $[15,62,64,65]$ showed a significant reduction $(\mathrm{WMD}=-7.42 ; 95 \% \mathrm{CI},-11.89$ to $-2.94 ; P=0.001$ ), although low-quality trials had no effect $(P=0.45)$. The test for subgroup differences in hospital LOS showed a significant difference between both subgroups $(P=0.001)$. Finally, there were no differences between high- and low-quality trials with regard to ICU $\operatorname{LOS}(P=0.86)$.

\section{Discussion}

Systemic inflammation and immune dysfunction are two key features in critical illness. In this context, it may be that provision of parenteral FO-containing LEs in ICU patients receiving PN or EN (pharmaconutrient strategy) represents a promising and attractive therapeutic option. We have updated our previous systematic review by evaluating the effects of FO-containing LEs on relevant clinical outcomes in ten eligible RCTs [15-18,61-66] involving critically ill patients. The main findings of our 


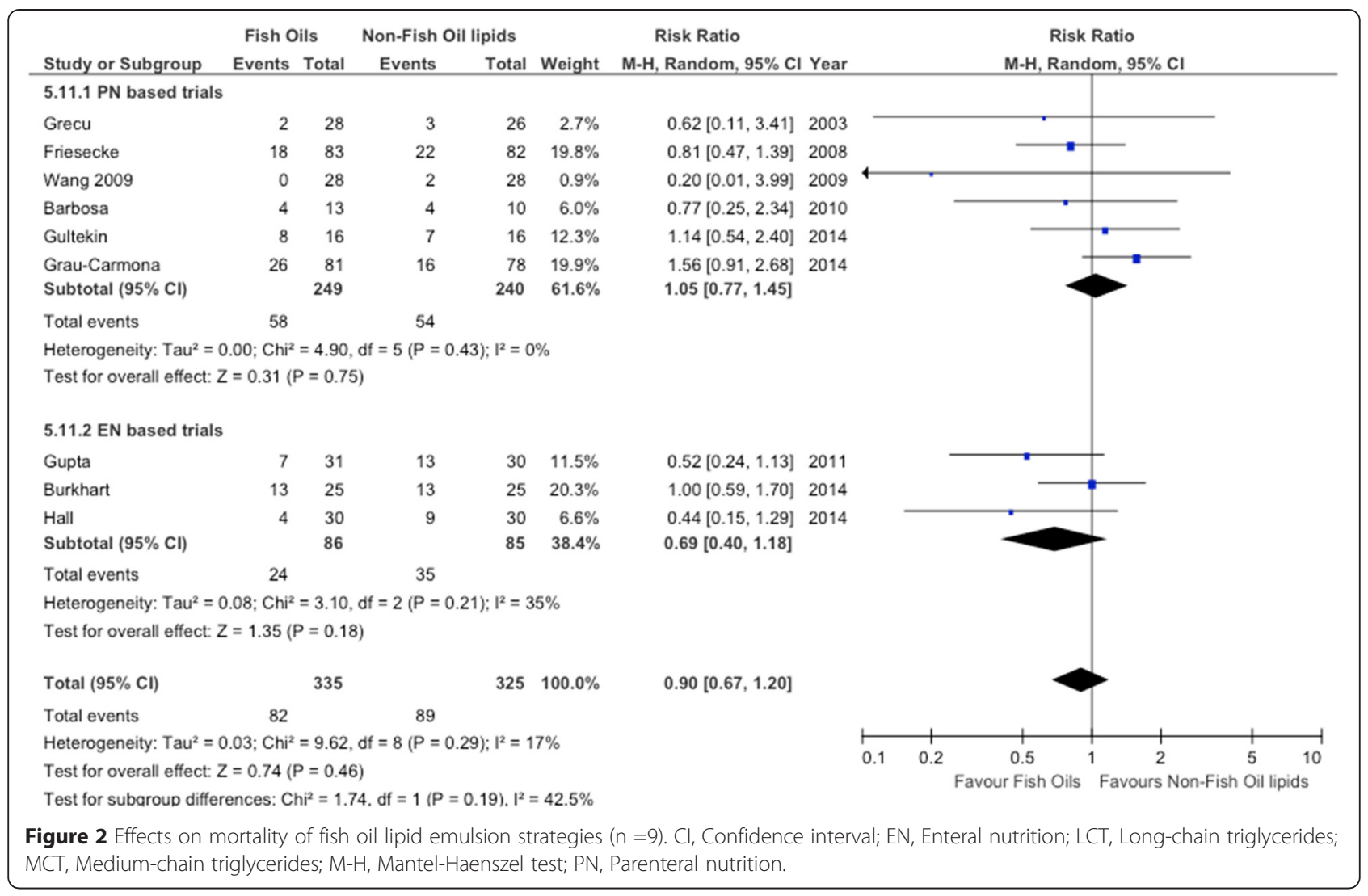

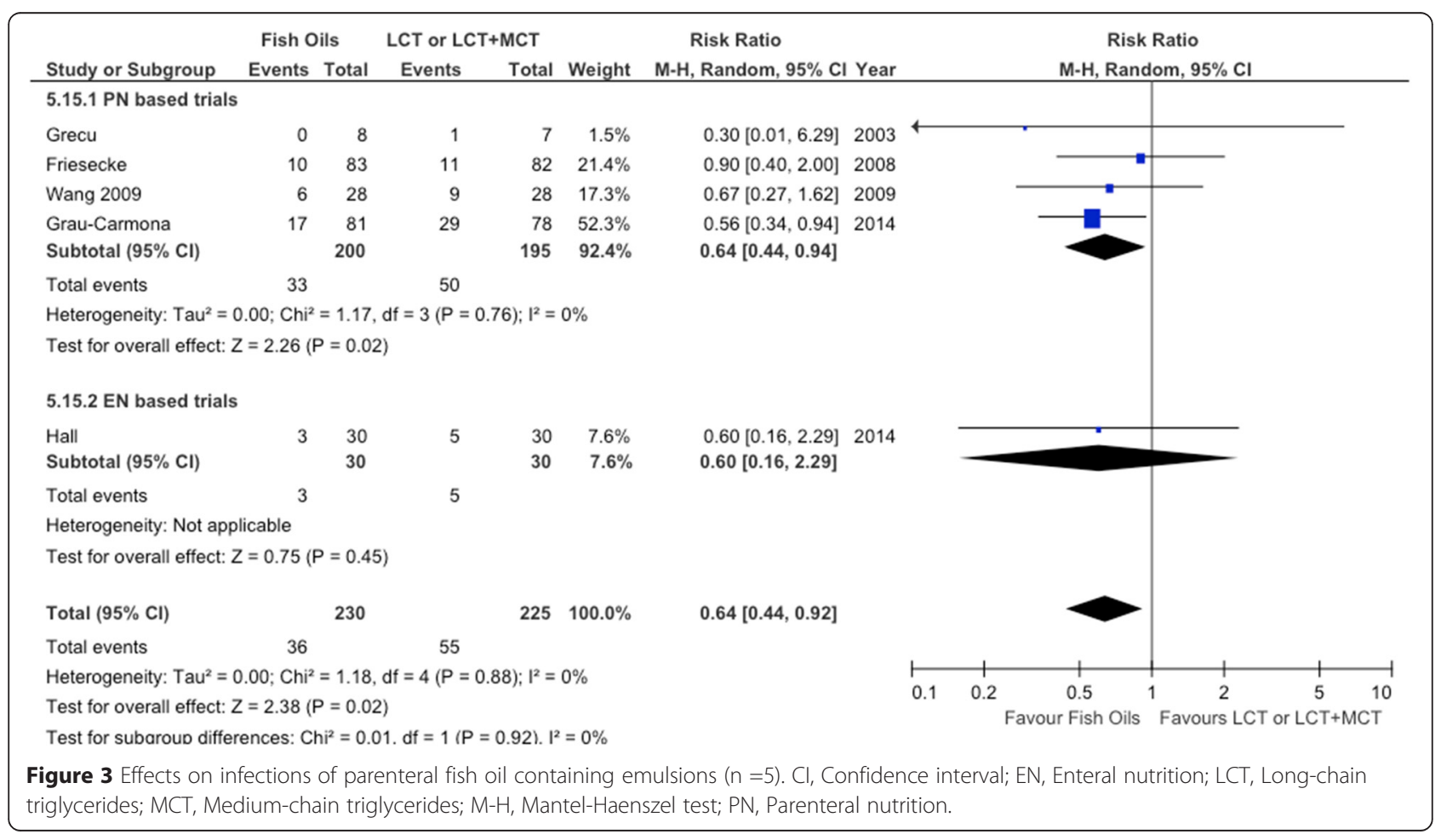




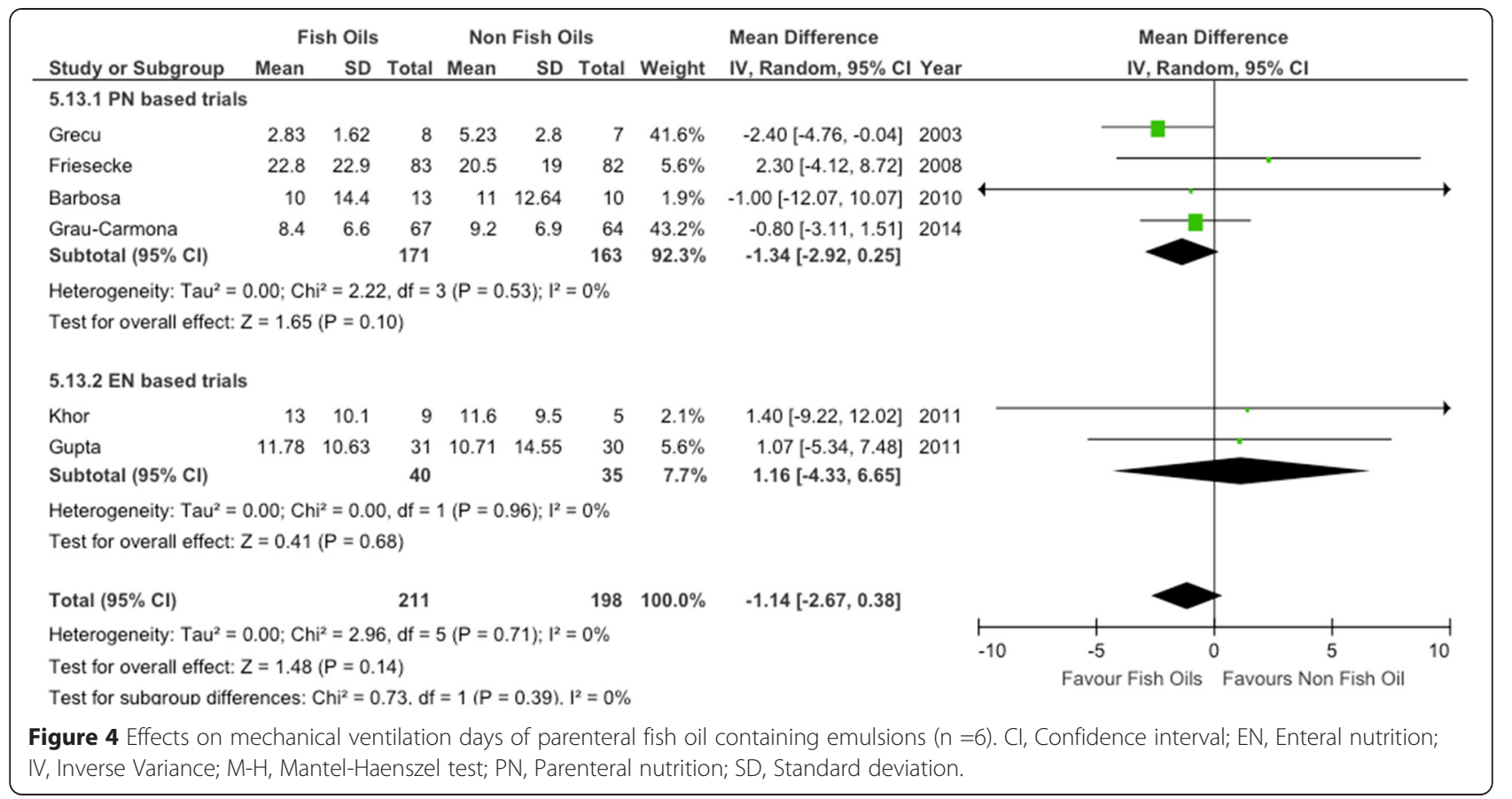

meta-analysis are that FO-containing LEs may reduce infections and may be associated with a tendency toward fewer MV days compared with SO-based strategies or administration of other alternative LEs in ICU patients. Nonetheless, contrary to our previous findings [10], we did not find a tendency toward reduced mortality, although in EN-based trials FO-containing LEs as pharmaconutrition may be associated with a tendency toward reduced mortality. The benefit in terms of improvement in recovery times, as indicated by the tendency toward a reduction in MV days and hospital LOS, may be due to reduced infections, generally or specifically a lower incidence of VAP, which is a frequent cause of infection in mechanically ventilated patients and is associated with significant attributable morbidity and mortality [67]. The presently reported results notwithstanding, these outcomes should be explored in further well-conducted and adequately powered RCTs.

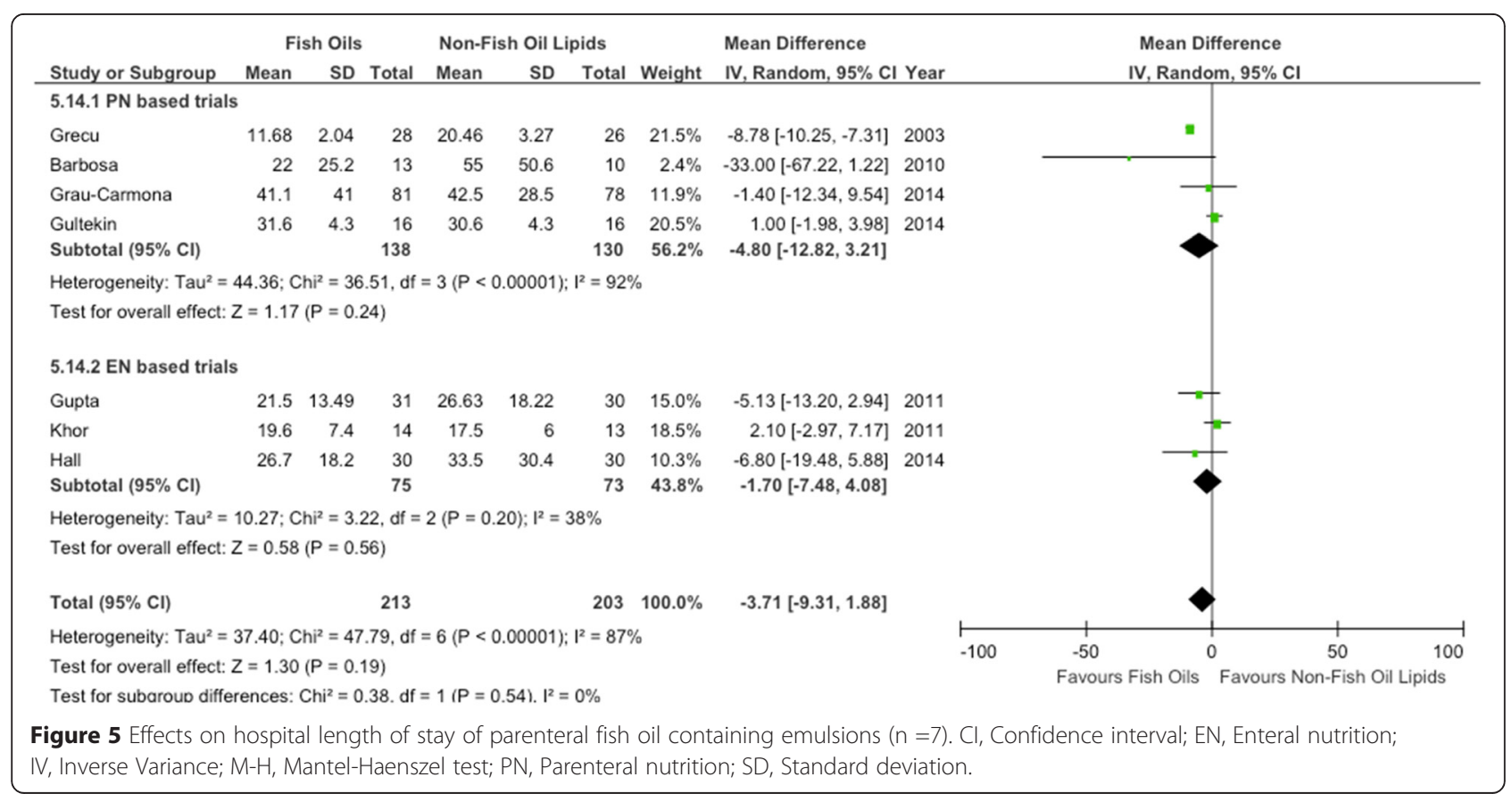




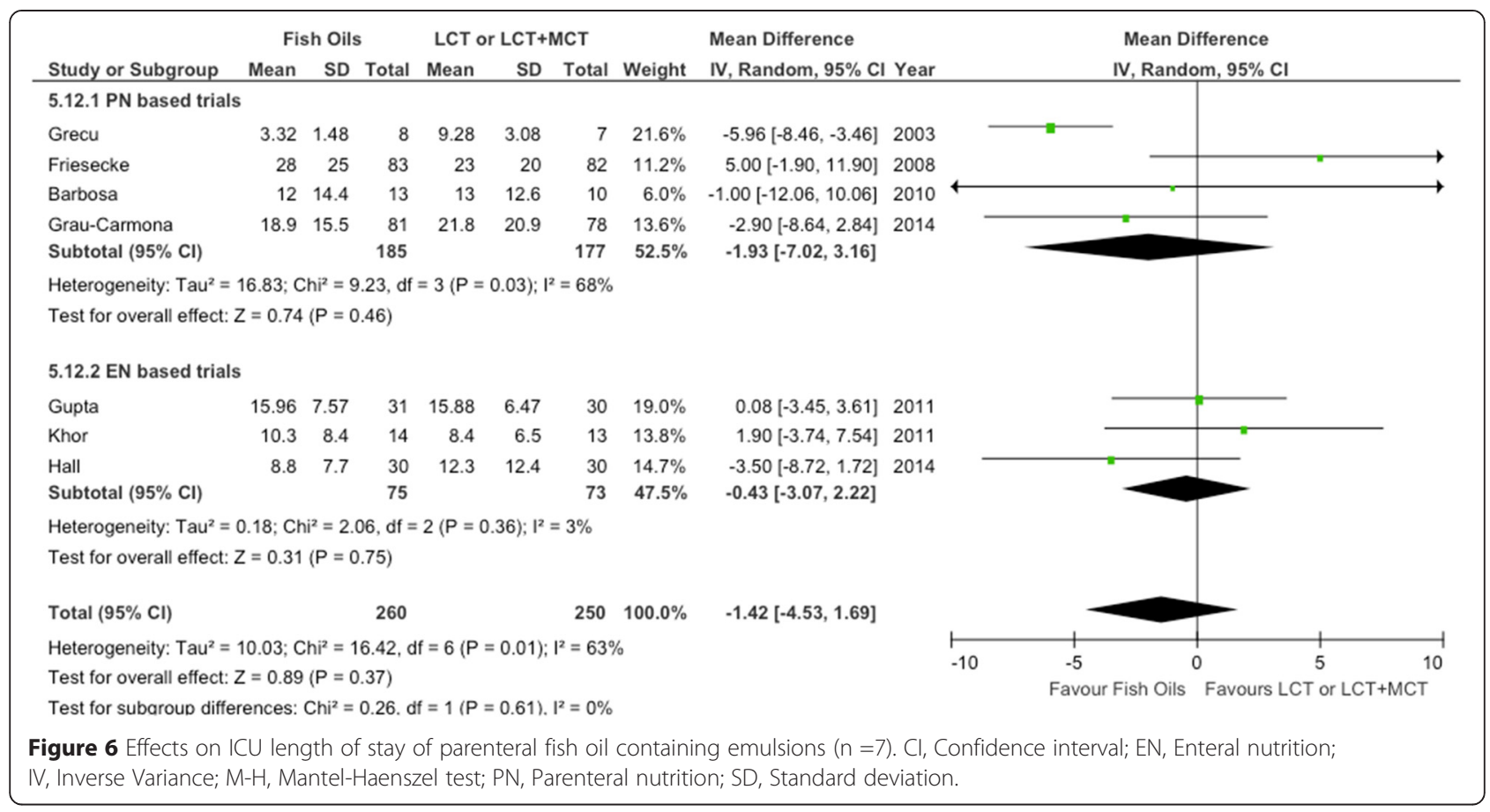

So far, our systematic review and meta-analysis is the most updated evaluation of the overall effects of FObased PN strategies in the critically ill. In addition, it is pertinent for intensive care as, according to our inclusion criteria, it contains only RCTs evaluating clinical outcomes in ICU patients. Unfortunately, with the exception of two trials $[63,65]$, most trials included in this systematic review were relatively small studies with fewer than 100 patients and therefore were inadequate to detect a clinically important treatment effect of FOcontaining LEs on mortality. However, the advantage of meta-analytic techniques is that they can combine data across studies to discern a more precise treatment effect. In addition, given the wide variety of clinical diagnoses and the heterogeneous population of ICU patients included in this systematic review (sepsis, severe sepsis and/or septic shock, trauma, cancer, pancreatitis, and systemic inflammatory response syndrome), the results and conclusions may be applied to a broad and heterogeneous group of ICU patients.

Since 2012, different meta-analyses $[8,9,60]$ on FOenriched PN have been published. The differences with our present review are largely due to the variations in the studies included in the reviews. In 2012, Pradelli et al. [8] statistically aggregated 23 RCTs in elective surgery and critically ill patients, and, similarly to our findings, they demonstrated that FO-based PN strategies were associated with a significant reduction in infections $(\mathrm{RR}=0.61$; 95\% CI, 0.45 to $0.84 ; P=0.002$ ). Furthermore, Pradelli et al. [8] showed a statistically and clinically significant effect on LOS, both in the ICU (WMD $=-1.92 ; 95 \%$ CI,
-3.27 to $-0.58 ; P=0.005)$ and in the hospital (WMD = -3.29 ; $95 \% \mathrm{CI},-5.13$ to $-1.45 ; P=0.0005)$, although no effect on overall mortality was found. The results regarding infections in the Pradelli et al. study [8] are very similar to our findings, although the inclusion criteria were different, as Pradelli et al. included ten trials in adult patients undergoing elective major abdominal surgery and not admitted to the ICU $(\mathrm{n}=740)$. Meanwhile, after aggregating nine RCTs on FO-containing LEs in ICU patients receiving PN, Palmer et al. [9] were unable to demonstrate any significant effect on infectious complications ( $R R=0.78 ; 95 \%$ CI, 0.43 to $1.41 ; P=0.41$ ) or on mortality and ICU LOS. Palmer et al. [9] included studies published by Wang et al. in 2008 [33] and 2009 [61]. However, we excluded the 2008 Wang et al. trial [33] because we included a later version of the study that included more patients [61]. Additionally, we excluded two unpublished trials, one by Leiderman et al. [54] and one by Ignatenko et al. [55]. Both of these trials $[54,55]$ were included in the prior meta-analyses, but they are published only as abstracts, and we were not able to obtain data from the investigators necessary to have these trials included in our review.

In 2014, Chen et al. [60] summarized 12 RCTs that administered $\omega-3$ PUFAs through enteral or parenteral routes in ICU patients and showed a tendency toward a reduction in mortality $(\mathrm{RR}=0.82,95 \% \mathrm{CI}, 0.62$ to 1.09 ; $P=0.18$ ), although the effect on other clinical outcomes was not analyzed [60].

Is it plausible that FO-containing LEs reduce infections? According to current knowledge, $\omega-3$ PUFAs have different effects on the function and gene expression of 
the immune cells, affecting cellular and humoral immunity $[2-4,6]$, which may explain their effects on infections in the critically ill. DHA generates protectins, D-series resolvins and maresins, whereas EPA generates E-series resolvins. The immunomodulatory effects of EPA and DHA, in contrast to the $\omega-6$ PUFAs, have been largely recognized for the ability of $\omega-3$ PUFAs to modify leukocyte activity, decrease cell membrane fluidity, alter the production of bioactive mediators and cell signaling, and modulate systemic inflammation by inhibition of cytokine release $[2,68]$. Intravenous infusion of FO-containing LEs rapidly leads to an incorporation of $\omega-3$ PUFAs in leukocyte cell membrane phospholipids, leading to a reduced production of proinflammatory cytokines because of a higher ratio of $\omega-3$ to $\omega-6$ PUFAs $[2,6]$.

In 2008, Liang et al. [32] supplemented patients undergoing radical colorectal cancer resection with FOenriched PN and showed a reduction in interleukin (IL)6 , a high $\mathrm{CD}^{+} / \mathrm{CD}^{+}$ratio, and higher $\mathrm{CD}^{+}$and $\mathrm{CD} 4^{+}$ lymphocytes. These findings suggest that supplementation of EPA and DHA by the parenteral route may support immunocompetent cells in seriously ill surgical patients. Meanwhile, Mayer et al. [52] demonstrated a significant improvement in neutrophil function in patients receiving FO-containing LEs, including leukotriene generation and respiratory burst. More recently, in a rat model of sepsis, Terashima et al. [69] demonstrated that FO-enriched PN may regulate neutrophil functions, restoring delayed apoptosis, which was associated with an increase in leukotriene B5 (LTB5) production from peritoneal neutrophils. Hecker et al. [70], in a very elegant murine model of acute respiratory distress syndrome, demonstrated, among other findings, that parenteral FO decreased leukocyte invasion, protein leakage, myeloperoxidase activity, and cytokine production in the alveolar space. Therefore, they have speculated that $\omega-3$ PUFAs could be beneficial in reducing pulmonary inflammatory complications such as VAP [70]. All of these experimental findings may explain, at least in part, the anti-inflammatory and immunomodulatory effects of $\omega-3$ PUFAs seen in clinical practice.

In sepsis, parenteral FO-containing LEs can result in favorable changes to inflammation and immunity by minimizing inflammation and maximizing resolution of inflammatory response and thus improving patient outcomes. However, resolvin D1 produced from DHA has several actions that stop polymorphonuclear neutrophil infiltration and inhibit microglial cells from expressing inflammatory cytokines in in vitro animal models. In addition, resolvin E1 decreases leukocyte infiltration induced by tumor necrosis factor (TNF)- $\alpha$ [71]. Therefore, oversuppression may potentially lead to immunosuppression, although there are conflicting data on the effect on cytokine expression and immunological markers, as no documented reports of negative hemostatic outcomes from FO-containing LEs in sepsis/ severe sepsis have been published.

The investigators in the clinical trials included in our systematic review evaluated mechanistic effects of FOcontaining LEs. Hall et al. [17] demonstrated a significant reduction in C-reactive protein (CRP) mean values in the FO-enriched PN group, although Burkhart et al. [18] were unable to find differences in IL-6, IL-8, IL-10 and CRP levels between patients supplemented and non-supplemented with FO. Meanwhile, after comparing two alternative LEs, Gultekin et al. [66] found a significant reduction in LTB4 and CRP levels in FO-supplemented patients, whereas IL- 6 and TNF- $\alpha$ levels were not different between groups. Previously, Barbosa et al. [64] demonstrated a significant reduction in plasma IL-6 and IL-10 levels in the FO group. Similarly, Wang et al. [61] showed an increase in IL-10 levels and human leukocyte antigen DR expression, as well as a concomitantly significant reduction in CRP levels, in patients with severe acute pancreatitis.

The strength of our meta-analysis is based on the fact that, as in previous meta-analyses, we used several methods to reduce bias (comprehensive literature search, duplicate data abstraction, specific criteria for searching and analysis) and focused on clinically important primary outcomes in ICU patients. Nevertheless, we are aware that our meta-analysis has several limitations, such as the limited number of trials included to evaluate different outcomes. In addition, the effect on infections is driven mostly by the large RCT by Grau-Carmona et al. $(\mathrm{N}=159)$ [65]. This trial explains $52 \%$ of the signal and is thus an unstable estimate, which increases slightly after the sensitivity analysis excluding the Hall et al. study [17] $(\mathrm{RR}=0.64 ; 95 \% \mathrm{CI}, 0.44$ to $0.94 ; P=0.02$; heterogeneity $I^{2}=0 \%$ ). In addition, most of data about MV days and ICU and hospital LOS were extracted from the original reports, which may underestimate the average duration in those cases where LOS of non-survivors was included in the calculation. Finally, there are two unpublished abstracts $[54,55]$ from which we could not obtain sufficient data to include in our meta-analysis. These factors may limit the reliability of our estimates and weaken the strength of our conclusions.

\section{Conclusions}

In this updated systematic review and meta-analysis, we demonstrate that parenteral FO-containing LEs in critically ill patients may be able to significantly reduce the incidence of infectious complications and also could be associated with a reduction in the duration of MV and hospital LOS. Our results are generalizable to patients receiving some form of artificial nutrition in the ICU setting. Nevertheless, according to the current literature, 
there is inadequate evidence to give a strong recommendation on the routine use of FO-containing LEs in PN and/or as a pharmaconutrient strategy in enterally fed critically ill patients. Additional large-scale and welldesigned RCTs, which should be aimed at confirming our observations, are required and warranted.

\section{Key messages}

- Intravenous FO-containing LEs are rich in $\omega-3$ PUFAs, which exhibit anti-inflammatory and immunomodulatory effects.

- These FO-containing strategies may be able to significantly reduce the incidence of infectious complications and also could be associated with a reduction in the duration of MV and hospital LOS in critically ill patients.

- FO-containing LEs as pharmaconutrient strategies in enterally fed patients may be able to reduce mortality.

- So far, there is inadequate evidence to give a final recommendation on the use of FO-containing LEs as a $\omega-6$ fatty acid-reducing strategy in ICU patients who require $\mathrm{PN}$ and/or as a pharmaconutrient strategy in enterally or orally fed patients.

\section{Abbreviations}

ARDS: Acute respiratory distress syndrome; Cl: Confidence interval; C.Random: Concealed randomization; CRP: C-reactive protein; DHA: Docosahexaenoic acid; EN: Enteral nutrition; EPA: Eicosapentaenoic acid; FO: Fish oil; ICU: Intensive care unit; IL: Interleukin; ITT: Intention to treat; LCT: Long-chain triglyceride; LE: Lipid emulsion; LOS: Length of stay; LTB4: Leukotriene B4; LTB5: Leukotriene B5; MCT: Medium-chain triglyceride; MV: Mechanical ventilation; NA: Non-attributable; NR: Non-reported; OO: Olive oil; PN: Parenteral nutrition; PO: Oral nutrition;

PUFA: Polyunsaturated fatty acid; RCT: Randomized controlled trial; RR: Risk ratio; SIRS: Systemic inflammatory response syndrome; SO: Soybean oil; TNF: Tumor necrosis factor; TPN: Total parenteral nutrition; VAP: Ventilatorassociated pneumonia; WMD: Weighted mean difference.

\section{Competing interests}

DKH received a speaking honorarium and research grants from Fresenius Kabi (Bad Homburg, Germany), a company that manufactures Omegaven, a 100\% pure FO emulsion. The other authors declare that they have no competing interests. No funding for the development, writing or submission of this manuscript was received.

\footnotetext{
Authors' contributions

WM contributed to the development of the manuscript concept, study grading, study selection, evaluation, and interpretation of data and performed primary writing and editing of all drafts of the manuscript. PLL contributed to the development of the manuscript concept, study grading, study selection, evaluation, and interpretation of data. RD contributed to the development of the manuscript concept, study grading, study selection, evaluation, and interpretation of data and performed statistical analysis, meta-analysis and data analysis. ML performed much of the primary statistical analysis and meta-analysis data analysis and contributed to study selection and evaluation and interpretation of data. DKH contributed to the development of the manuscript concept, study grading, study selection, evaluation, and interpretation of data and performed editing of all drafts of the manuscript. All authors read and approved the final manuscript.
}

\section{Author details}

'Intensive Care Unit, Faculty of Medicine-Universidad de la República (UdeLaR) University Hospital: Dr. Manuel Quintela, Italia Av. 14th Floor, Montevideo 11600, Uruguay. ${ }^{2}$ Département de Anesthésie et de Réanimation, Faculté de Médecine et des Sciences de la Santé, Université de Sherbrooke, Centre Hospitalier Universitaire de Sherbrooke-Hôpital Fleurimont, Sherbrooke, PQ, Canada. ${ }^{3}$ Clinical Evaluation Research Unit, Kingston General Hospital, Kingston, ON, Canada. ${ }^{4}$ Department of Medicine, Queen's University, Kingston, ON, Canada.

Received: 17 December 2014 Accepted: 17 March 2015

Published online: 16 April 2015

\section{References}

1. Carpentier YA, Dupont IE. Advances in intravenous lipid emulsions. World J Surg. 2000;24:1493-7.

2. Wanten GJ, Calder PC. Immune modulation by parenteral lipid emulsions. Am J Clin Nutr. 2007:85:1171-84.

3. Hecker M, Mayer K. Intravenous lipids in adult intensive care unit patients. World Rev Nutr Diet. 2015;112:120-6.

4. Calder PC, Jensen GL, Koletzko BV, Singer P, Wanten GJA. Lipid emulsions in parenteral nutrition of intensive care patients: current thinking and future directions. Intensive Care Med. 2010;36:735-49.

5. Ren T, Cong L, Wang Y, Tang Y, Tian B, Lin X, et al. Lipid emulsions in parenteral nutrition: current applications and future developments. Expert Opin Drug Deliv. 2013;10:1533-49.

6. Waitzberg DL, Torrinhas RS. Fish oil lipid emulsions and immune response: what clinicians need to know. Nutr Clin Pract. 2009;24:487-99.

7. Edmunds CE, Brody RA, Parrott JS, Stankorb SM, Heyland DK. The effects of different IV fat emulsions on clinical outcomes in critically ill patients. Crit Care Med. 2014;42:1168-77.

8. Pradelli L, Mayer K, Muscaritoli M, Heller AR. n-3 fatty acid enriched parenteral nutrition regimens in elective surgical and ICU patients: a meta-analysis. Crit Care. 2012;16:R184.

9. Palmer AJ, Ho CKM, Ajibola O, Avenell A. The role of n-3 fatty acid supplemented parenteral nutrition in critical illness in adults: a systematic review and meta-analysis. Crit Care Med. 2013;41:307-16.

10. Manzanares W, Dhaliwal R, Jurewitsch B, Stapleton RD, Jeejeebhoy KN, Heyland DK. Parenteral fish oil lipid emulsions in the critically ill: a systematic review and meta-analysis. JPEN J Parenter Enteral Nutr. 2014;38:20-8.

11. Heyland DK, MacDonald S, Keefe L, Drover JW. Total parenteral nutrition in the critically ill patient: a meta-analysis. JAMA. 1998;280:2013-9.

12. DerSimonian R, Laird N. Meta-analysis in clinical trials. Control Clin Trials. 1986:7:177-88.

13. Deeks J, Higgins PT. Statistical algorithms in Review Manager 5. 2010. http://ims.cochrane.org/revman/documentation/Statistical-methods-inRevMan-5.pdf. Accessed 8 Apr 2015.

14. Rücker $G$, Schwarzer $G$, Carpenter J. Arcsine test for publication bias in meta-analyses with binary outcomes. Stat Med. 2008;27:746-63.

15. Gupta A, Govil D, Bhatnagar S, Gupta S, Goyal J, Patel S, et al. Efficacy and safety of parenteral omega 3 fatty acids in ventilated patients with acute lung injury. Indian J Crit Care Med. 2011;15:108-13.

16. Khor BS, Liaw SJ, Shih HC, Wang LS. Randomized, double blind, placebocontrolled trial of fish-oil-based lipid emulsion infusion for treatment of critically ill patients with severe sepsis. Asian J Surg. 2011;34:1-10.

17. Hall TC, Bilku DK, Al-Leswas D, Neal CP, Horst C, Cooke J, et al. A randomized controlled trial investigating the effects of parenteral fish oil on survival outcomes in critically ill patients with sepsis: a pilot study. JPEN J Parenter Enteral Nutr. 2015;39:301-12.

18. Burkhart CS, Dell-Kuster S, Siegemund M, Pargger H, Marsch S, Strebel SP et al. Effect of $\mathrm{n}-3$ fatty acids on markers of brain injury and incidence of sepsis-associated delirium in septic patients. Acta Anaesthesiol Scand. 2014;58:689-700

19. Wachtler P, König W, Senkal M, Kemen M, Köller M. Influence of a total parenteral nutrition enriched with omega-3 fatty acids on leukotriene synthesis of peripheral leukocytes and systemic cytokine levels in patients with major surgery. J Trauma. 1997;42:191-8.

20. Gogos CA, Ginopoulos P, Salsa B, Apostolidou E, Zoumbos NC, Kalfarentzos F. Dietary omega-3 polyunsaturated fatty acids plus vitamin E restore immunodeficiency and prolong survival for severely ill patients with generalized malignancy: a randomized control trial. Cancer. 1998;82:395-402. 
21. Furukawa K, Tashiro T, Yamamori H, Takagi K, Morishima Y, Sugiura T, et al. Effects of soybean oil emulsion and eicosapentaenoic acid on stress response and immune function after a severely stressful operation. Ann Surg. 1999;229:255-61.

22. Linseisen J, Hoffmann J, Lienhard S, Jauch KW, Wolfram G. Antioxidant status of surgical patients receiving TPN with an $\Omega$-3-fatty acid-containing lipid emulsion supplemented with a-tocopherol. Clin Nutr. 2000;19:177-84.

23. Heller AR, Fischer S, Rössel T, Geiger $S$, Siegert G, Ragaller M, et al. Impact of n-3 fatty acid supplemented parenteral nutrition on haemostasis patterns after major abdominal surgery. Br J Nutr. 2002;87:S95-S101.

24. Heller AR, Rössel T, Gottschlich B, Tiebel O, Menschikowski M, Litz RJ, et al. Omega-3 fatty acids improve liver and pancreas function in postoperative cancer patients. Int J Cancer. 2004;111:611-6.

25. Klek S, Kulig J, Szczepanik AM, Jedrys J, Kołodziejczyk P. The clinical value of parenteral immunonutrition in surgical patients. Acta Chir Belg. 2005;105:175-9.

26. Grimm H, Mertes N, Goeters C, Schlotzer E, Mayer K, Grimminger F, et al. Improved fatty acid and leukotriene pattern with a novel lipid emulsion in surgical patients. Eur J Nutr. 2006:45:55-60.

27. Mertes N, Grimm H, Fürst P, Stehle P. Safety and efficacy of a new parenteral lipid emulsion (SMOFlipid) in surgical patients: a randomized, double-blind, multicenter study. Ann Nutr Metab. 2006;50:253-9.

28. Senkal M, Geier B, Hannemann M, Deska T, Linseisen J, Wolfram G, et al. Supplementation of $\Omega-3$ fatty acids in parenteral nutrition beneficially alters phospholipid fatty acid pattern. JPEN J Parenter Enteral Nutr. 2007:31:12-7.

29. Wendel M, Rössel T, Bergmann S, Otto S, Ragaller M, Zimmermann T, et al. Impact of total parenteral nutrition including omega-3 fatty acids on the regulation of plasma lipoproteins and glycemic control after major abdominal surgery. ESPEN J. 2007;2:e103-10.

30. Wichmann MW, Thul P, Czarnetzki HD, Morlion BJ, Kemen M, Jauch KW. Evaluation of clinical safety and beneficial effects of a fish oil containing lipid emulsion (Lipoplus, MLF541): data from a prospective, randomized, multicenter trial. Crit Care Med. 2007;35:700-6.

31. Berger MM, Tappy L, Revelly JP, Koletzko BV, Gepert J, Corpataux JM, et al. Fish oil after abdominal aorta aneurysm surgery. Eur J Clin Nutr. 2008;62:1116-22

32. Liang $B$, Wang $S$, Ye $Y$ J, Yang $X D$, Wang $Y L$, Qu J, et al. Impact of postoperative omega-3 fatty acid-supplemented parenteral nutrition on clinical outcomes and immunomodulations in colorectal cancer patients. World J Gastroenterol. 2008;14:2434-9.

33. Wang X, Li W, Li N, Li J. $\omega-3$ fatty acids-supplemented parenteral nutrition decreases hyperinflammatory response and attenuates systemic disease sequelae in severe acute pancreatitis: a randomized and controlled study. JPEN J Parenter Enteral Nutr. 2008;32:236-41.

34. Heidt MC, Vician M, Stracke SK, Stadlbauer T, Grebe MT, Boening A, et al. Beneficial effects of intravenously administered N-3 fatty acids for the prevention of atrial fibrillation after coronary artery bypass surgery: a prospective randomized study. Thorac Cardiovasc Surg. 2009;57:276-80.

35. Piper SN, Schade I, Beschmann R, Maleck W, Boldt J, Röhm KD. Hepatocellular integrity after parenteral nutrition: comparison of a fish-oilcontaining lipid emulsion with olive-soybean oil-based lipid emulsion. Eur J Anaesthesiol. 2009;26:1076-82.

36. Puiggròs $C$, Sánchez J, Chacón P, Sabín P, Roselló J, Bou R, et al. Evolution of lipid profile, liver function, and pattern of plasma fatty acids according to the type of lipid emulsion administered in parenteral nutrition in the early postoperative period after digestive surgery. JPEN J Parenter Enteral Nutr. 2009;33:501-12.

37. Badía-Tahull MB, Llop-Talaverón JM, Leiva-Badosa E, Biondo S, Farran-Teixidó $L$, Ramón-Torrell JM, et al. A randomised study on the clinical progress of high-risk elective major gastrointestinal surgery patients treated with olive oil-based parenteral nutrition with or without a fish oil supplement. Br J Nutr. 2010;104:737-41.

38. Jiang ZM, Wilmore DW, Wang XR, Wei JM, Zhang ZT, Gu ZY, et al. Randomized clinical trial of intravenous soybean oil alone versus soybean oil plus fish oil emulsion after gastrointestinal cancer surgery. Br J Surg. 2010;97:804-9.

39. Han YY, Lai SL, Ko WJ, Chou CH, Lai HS. Effects of fish oil on inflammatory modulation in surgical intensive care unit patients. Nutr Clin Pract. 2012;27:91-8.
40. Zhu MW, Tang DN, Hou J, Wei JM, Hua B, Sun JH, et al. Impact of fish oil enriched total parenteral nutrition on elderly patients after colorectal cancer surgery. Chin Med J. 2012;125:178-81.

41. Matos de Miranda Torrinhas RS, Santana R, Garcia T, Cury-Boaventura MF, Sales MM, Curi R, et al. Parenteral fish oil as a pharmacological agent to modulate post-operative immune response: a randomized, double-blind, and controlled clinical trial in patients with gastrointestinal cancer. Clin Nutr. 2013;32:503-10.

42. Long $H$, Yang H, Lin Y, Situ D, Liu W. Fish oil-supplemented parenteral nutrition in patients following esophageal cancer surgery: effect on inflammation and immune function. Nutr Cancer. 2013;65:71-5.

43. Zhu $X$, Wu $Y$, Qiu $Y$, Jiang $C$, Ding $Y$. Effect of parenteral fish oil lipid emulsion in parenteral nutrition supplementation combined with enteral nutrition support in patients undergoing pancreaticoduodenectomy. JPEN J Parenter Enteral Nutr. 2013;37:236-42.

44. Adams S, Yeh YY, Jensen GL. Changes in plasma and erythrocyte fatty acids in patients fed enteral formulas containing different fats. JPEN J Parenter Enteral Nutr. 1993;17:30-4.

45. Schauder P, Röhn U, Schäfer G, Korff G, Schenk HD. Impact of fish oil enriched total parenteral nutrition on DNA synthesis, cytokine release and receptor expression by lymphocytes in the postoperative period. $\mathrm{Br} J$ Nutr. 2002;87 Suppl 1:S103-10.

46. Köller M, Senkal M, Kemen M, König W, Zumtobel V, Muhr G. Impact of omega-3 fatty acid enriched TPN on leukotriene synthesis by leukocytes after major surgery. Clin Nutr. 2003;22:59-64

47. Mayer K, Meyer S, Reinholz-Muhly M, Maus U, Merfels M, Lohmeyer J, et al. Short-time infusion of fish oil-based lipid emulsions, approved for parenteral nutrition, reduces monocyte proinflammatory cytokine generation and adhesive interaction with endothelium in humans. J Immunol. 2003;171:4837-43.

48. Antébi H, Mansoor O, Ferrier C, Tétégan M, Morvan C, Rangaraj J, et al. Liver function and plasma antioxidant status in intensive care unit patients requiring total parenteral nutrition: comparison of 2 fat emulsions. JPEN J Parenter Enteral Nutr. 2004;28:142-8.

49. Tappy L, Berger MM, Schwarz JM, Schneiter P, Kim S, Revelly JP, et al. Metabolic effects of parenteral nutrition enriched with n-3 polyunsaturated fatty acids in critically ill patients. Clin Nutr. 2006;25:588-95.

50. Xiong J, Zhu S, Zhou Y, Wu H, Wang C. Regulation of $\omega-3$ fish oil emulsion on the SIRS during the initial stage of severe acute pancreatitis. J Huazhong Univ Sci Technolog Med Sci. 2009;29:35-8.

51. Sungurtekin H, Değirmenci S, Sungurtekin U, Oguz BE, Sabir N, Kaptanoglu B. Comparison of the effects of different intravenous fat emulsions in patients with systemic inflammatory response syndrome and sepsis. Nutr Clin Pract. 2011;26:665-71.

52. Mayer K, Fegbeutel C, Hattar K, Sibelius U, Krämer HJ, Heuer KU, et al. $\omega-3$ vs. $\omega-6$ lipid emulsions exert differential influence on neutrophils in septic shock patients: impact on plasma fatty acids and lipid mediator generation. Intensive Care Med. 2003;29:1472-81.

53. Mayer K, Gokorsch S, Fegbeutel C, Hattar K, Rosseau S, Walmrath D, et al. Parenteral nutrition with fish oil modulates cytokine response in patients with sepsis. Am J Respir Crit Care Med. 2003;167:1321-8.

54. Leiderman I, Malkova O, Levit A. Omega 3 enriched lipid emulsion decreases APACHE II and SOFA scores values in abdominal sepsis patients [abstract PP018]. Clin Nutr Suppl. 2010;5:30.

55. Ignatenko O, Yaroshetskiy A, Masolitin S, Protsenko D, Gelfand B. Fish oil treatment in severe trauma patients. Intensive Care Med. 2010;36 Supplement 2:S316.

56. Larsen BM, Goonewardene LA, Joffe AR, Van Aerde JE, Field CJ, Olstad DL, et al. Pre-treatment with an intravenous lipid emulsion containing fish oil (eicosapentaenoic and docosahexaenoic acid) decreases inflammatory markers after open-heart surgery in infants: a randomized, controlled trial. Clin Nutr. 2012;31:322-9.

57. Beken S, Dilli D, Fettah ND, Kabataş EU, Zenciroğlu A, Okumuş N. The influence of fish-oil lipid emulsions on retinopathy of prematurity in very low birth weight infants: a randomized controlled trial. Early Hum Dev. 2013;90:27-31.

58. Sabater J, Masclans JP, Sacanell J, Chacon P, Sabin P, Planas M. Effects on hemodynamics and gas exchange of omega-3 fatty acid-enriched lipid emulsion in acute respiratory distress syndrome (ARDS): a prospective, randomized, double-blind, parallel group study. Lipids Health Dis. 2008;7:39.

59. Taftachi F, Sanaei-Zadeh H, Sepehrian B, Zamani N. Lipid emulsion improves Glasgow coma scale and decreases blood glucose level in the setting of 
acute non-local anesthetic drug poisoning: randomized controlled trial. Eur Rev Med Pharmacol Sci. 2012;16:38-42.

60. Chen W, Jiang H, Zhou ZY, Tao YX, Cai B, Liu J, et al. Is omega-3 fatty acids enriched nutrition support safe for critical ill patients? A systematic review and meta-analysis. Nutrients. 2014;6:2148-64.

61. Wang X, Li W, Zhang F, Pan L, Li N, Li J. Fish oil-supplemented parenteral nutrition in severe acute pancreatitis patients and effects on immune function and infectious risk: a randomized controlled trial. Inflammation. 2009;32:304-9.

62. Grecu I, Mirea L, Grintescu I. Parenteral fish oil supplementation in patients with abdominal sepsis [abstract]. Clin Nutr. 2003;22 Suppl 1:S23.

63. Friesecke S, Lotze C, Köhler J, Heinrich A, Felix SB, Abel P. Fish oil supplementation in the parenteral nutrition of critically ill medical patients: a randomised controlled trial. Intensive Care Med. 2008;34:1411-20.

64. Barbosa VM, Miles EA, Calhau C, Lafuente E, Calder PC. Effects of fish oil containing lipid emulsion on plasma phospholipid fatty acids, inflammatory markers, and clinical outcomes in septic patients: a randomized, controlled clinical trial. Crit Care. 2010;14:R5.

65. Grau-Carmona T, Bonet-Saris A, García-de-Lorenzo A, Sánchez-Alvarez C, Rodríguez-Pozo A, Acosta-Escribano J, et al. Influence of n-3 polyunsaturated fatty acids enriched lipid emulsions on nosocomial infections and clinical outcomes in critically ill patients: ICU Lipids Study. Crit Care Med. 2015:43:31-9.

66. Gultekin G, Sahin H, Inanc N, Uyanik F, Ok E. Impact of Omega-3 and Omega-9 fatty acids enriched total parenteral nutrition on blood chemistry and inflammatory markers in septic patients. Pak J Med Sci. 2014;30:299-304.

67. Kalanuria AA, Zai W, Mirski M. Ventilator-associated pneumonia in the ICU. Critical Care. 2014;18:208

68. Singer P, Shapiro H, Theilla M, Anbar R, Singer J, Cohen J. Antiinflammatory properties of omega-3 fatty acids in critical illness: novel mechanisms and an integrative perspective. Intensive Care Med. 2008;34:1580-92.

69. Terashima M, Aoyama-Ishikawa M, Ueda T, Hagi A, Usami M, Nakao A, et al. The effects of n-3 polyunsaturated fatty acid-rich total parenteral nutrition on neutrophil apoptosis in a rat endotoxemia. J Clin Biochem Nutr. 2013:52:154-9.

70. Hecker M, Ott J, Sondermann C, Schaefer MB, Obert M, Hecker A, et al. Immunomodulation by fish-oil containing lipid emulsions in murine acute respiratory distress syndrome. Crit Care. 2014;18:R85.

71. Arita M, Bianchini F, Aliberti J, Sher A, Chiang N, Hong S, et al. Stereochemical assignment, antiinflammatory properties, and receptor for the omega-3 lipid mediator resolvin E1. J Exp Med. 2005;201:713-22.

72. Moher D, Cook DJ, Eastwood S, Olkin I, Rennie D, Stroup DF. Improving the quality of reports of meta-analyses of randomized controlled trials: the QUOROM statement. Lancet. 1999;354:1896-900.

\section{Submit your next manuscript to BioMed Central and take full advantage of:}

- Convenient online submission

- Thorough peer review

- No space constraints or color figure charges

- Immediate publication on acceptance

- Inclusion in PubMed, CAS, Scopus and Google Scholar

- Research which is freely available for redistribution

Submit your manuscript at www.biomedcentral.com/submit 